INTESTINE INFLAMMATION

\title{
Lactic acid bacteria secrete metabolites retaining anti-inflammatory properties after intestinal transport
}

\author{
S Ménard, C Candalh, J C Bambou, K Terpend, N Cerf-Bensussan, M Heyman
}

Gut 2004;53:821-828. doi: 10.1136/gut.2003.026252

See end of article for authors' affiliations

Correspondence to:

Dr M Heyman, INSERM

EMI 0212, Faculté

Necker-Enfants Malades,

156 rue de Vaugirard,

75730 Paris, France:

heyman@necker.fr

Accepted for publication

14 December 2003
Background: Probiotic bacteria have a beneficial effect on intestinal inflammation. In this study, we have examined the effect of lactic acid and commensal Gram positive (+) bacteria conditioned media (CM) on tumour necrosis factor $\alpha$ (TNF- $\alpha$ ) release and the mechanisms involved.

Methods: Lipopolysaccharide (LPS) induced TNF- $\alpha$ secretion by peripheral blood mononuclear cells or the THP-1 cell line was monitored in the presence or absence of bacteria CM obtained from two probiotic strains, Bifidobacterium breve (Bb) and Streptococcus thermophilus (St), and three commensal bacterial strains (Bifidobacterium bifidum, Ruminococcus gnavus, and unidentified Streptococcus). Bb and St bacteria CM were allowed to cross filter grown intestinal epithelial cell monolayers (HT29-19A) to assess intestinal transport of active bacterial products. These products were characterised and their effect on LPS binding to THP-1 cells and nuclear factor $\kappa B(N F \kappa B)$ activation assessed.

Results: Dose dependent inhibition of LPS induced TNF- $\alpha$ secretion was noted for both probiotic bacteria $\mathrm{CM}$ (64\% and $71 \%$ inhibition for $\mathrm{Bb}$ and St, respectively) and to a lesser extent commensal bacteria CM (21-32\% inhibition). Active products from $B b$ and St were resistant to digestive enzymes and had a molecular mass $<3000 \mathrm{Da}$. Their inhibitory effect was preserved after transepithelial transport across intestinal cell monolayers, mainly in inflammatory conditions. LPS-FITC binding to THP-1 cells and NFKB activation were significantly inhibited by $\mathrm{Bb}$ and $\mathrm{St} C \mathrm{CM}$.

Conclusion: $B$ breve and $S$ thermophilus release metabolites exerting an anti-TNF- $\alpha$ effect capable of crossing the intestinal barrier. Commensal bacteria also display a TNF- $\alpha$ inhibitory capacity but to a lesser extent. These results underline the beneficial effect of commensal bacteria in intestinal homeostasis and may explain the role of some probiotic bacteria in alleviating digestive inflammation.
$\mathrm{V}$ arious beneficial effects to human health have been attributed to probiotic bacteria, mainly at the intestinal level. ${ }^{1}$ There is convergent evidence suggesting that probiotics may have anti-inflammatory properties. Allergic inflammation can benefit from the use of probiotics as an adjunct to conventional treatment. Indeed, it was reported that cow's milk allergic infants, treated with extensively hydrolysed milk formula supplemented with Lactobacillus rhamnosus $G G$, had a better clinical score and less tumour necrosis factor $\alpha$ (TNF- $\alpha$ ) in their faeces than infants treated with the hydrolysed formula only. ${ }^{2}$ Gastric inflammation associated with Helicobacter pylori infection was improved by supplementing conventional treatment with probiotic bacteria. $^{3}$ Interestingly, different lactobacilli, bifidobacteria, or probiotic mixtures (VSL\#3) have been shown to alleviate digestive diseases in experimental animals ${ }^{4}{ }^{5}$ and in inflammatory bowel diseases in humans. ${ }^{6-8}$ In neonatal rats suffering from stress induced necrotising enterocolitis, preliminary administration of Bifidobacterium infantis was protective towards enterocolitis development. ${ }^{9}$ Recently, it was also shown that Lactobacillus rhamnosus GG conditioned media decreased TNF- $\alpha$ production by macrophages in vitro ${ }^{10}$ by a contact independent mechanism. However, clear beneficial effects still remain controversial. ${ }^{11}$ Other studies have stressed the specificity of bacterial strains in inducing anti- or proinflammatory cytokines. Indeed, some lactic acid bacteria, or their secretion products, orally administered in mice (Lactobacillus reuteri or Lactobacillus brevis), had a stimulatory effect on secretion of proinflammatory cytokines such as interleukin (IL) $-1 \beta$ and TNF- $\alpha .{ }^{12}$

Probiotics are generally administered via the oral route and the intestinal epithelial barrier restricts their interaction with the local immune system. The present study was aimed at characterising the anti-inflammatory (anti-TNF- $\alpha$ ) effect of the metabolites produced by two lactic acid bacteria (Bifidobacterium breve and Streptococcus thermophilus) compared with three commensal bacteria strains. Lactic acid bacteria metabolites were characterised and possible mechanisms for their anti-inflammatory properties were studied, as well as their capacity to cross the intestinal barrier under normal or inflammatory conditions.

\section{METHODS}

\section{Preparation of bacteria conditioned media}

Two lactic acid bacterial strains, Bifidobacterium breve (strain BbC50) and Streptococcus thermophilus (strain St065), and three bacterial strains isolated from the dominant Gram positive human microflora were used. The commensal bacterial strains provided by G Corthier (INRA, Jouy en Josas, France) comprised Bifidobacterium bifidum strain B536, originally isolated from the faecal flora of a healthy breast fed infant, Ruminococcus gnavus (FREI), isolated from the predominant faecal flora of a healthy adult, ${ }^{13}$ and a nonidentified streptococcus strain isolated from the faecal flora of a one month old infant (named here neonatal streptococcus). All bacterial strains were first cultured on brainheart medium (bifidobacteria and ruminococcus) or lactose enriched M20 medium (streptococcus). Bacteria were then

Abbreviations: FCS, fetal calf serum; IFN, interferon; IL, interleukin; LBP, LPS binding protein; LPS, lipopolysaccharide; LTA, lipoteichoic acid; $N F \kappa B$, nuclear factor $\kappa B$; $P B M C$, peripheral blood mononuclear cells; $S A B$, human serum $A B ; B b C M$, Bifidobacterium breve conditioned media; St CM, Streptococcus thermophilus conditioned media; TGF- $\beta$, transforming growth factor $\beta$; TNF- $\alpha$, tumour necrosis factor $\alpha$; TLR, tolllike receptor; IEC, intestinal epithelial cells 
collected by centrifugation and cultured over 48 hours in RPMI medium containing $20 \%$ fetal calf serum (FCS) and supplemented with 3\% inulin (bifidobacteria and ruminococcus) or 3\% D-glucose (streptococcus). Bacteria conditioned media (CM) were ultracentrifuged $(100000 \mathrm{~g}$, one hour, $4^{\circ} \mathrm{C}$ ), filtrated on $0.22 \mu \mathrm{m}$ membranes, and frozen $\left(-80^{\circ} \mathrm{C}\right)$ until use. Bacteria CM corresponded to $5 \times 10^{5}$ and $8 \times 10^{5} \mathrm{CFU} / \mathrm{ml}$ for $S$ thermophilus and $B$ breve, and to $2 \times 10^{6}$, $1.3 \times 10^{6}$, and $3.3 \times 10^{8} \mathrm{CFU} / \mathrm{ml}$ for $R$ gnavus, $B$ bifidum, and the neonatal streptococcus, respectively.

In experiments comparing the anti-TNF- $\alpha$ effect of probiotic or commensal bacteria CM, dilutions were performed in RPMI/FCS to obtain the same final concentration corresponding to $2.5 \times 10^{5} \mathrm{CFU} / \mathrm{ml}$. Commensal bacteria $\mathrm{CM}$ were also tested at high concentrations (that is, half diluted).

In some experiments, bacteria CM were treated with pepsin and trypsin $(0.15 \mathrm{mg} / \mathrm{ml})$ to hydrolyse proteins. To characterise the size of active bacterial products, we submitted bacteria CM to ultrafiltration through Centriplus YM-3 or YM-10 membranes that retain molecules larger than 3000 or $10000 \mathrm{Da}$, respectively. Retained and filtrated fractions were adjusted to the initial volume and frozen until use.

\section{Immune cell culture and experimental protocols}

Peripheral blood mononuclear cells (PBMC) of healthy patients were cultured in RPMI 1640 supplemented with $10 \%$ human serum $\mathrm{AB}$ (SAB), $10 \mathrm{mM}$ HEPES, 1 mM sodium pyruvate, $0.05 \mathrm{mM} \beta$-mercapto-ethanol, and $1 \%$ penicillinstreptomycin. In some cases, the THP-1 pro-monocytic cell line (ATCC No TIB-202) was cultured in the same culture media containing FCS. PBMC or THP-1 cells were seeded on 24 well (Falcon) plates at $5 \times 10^{5}$ cells/well. PBMC were allowed to adhere for one hour and were then stimulated with 1-1000 ng/ml lipopolysaccharide (LPS, ref L2654; Sigma, La verpillère, France) for four hours in the presence or absence of dilutions of native or treated (as described above) bacteria CM. After centrifugation, supernatants were collected and assayed for TNF- $\alpha$. In some cases, IL-10 secretion was also tested in the presence of bacteria CM and LPS. The optimal LPS concentration shown to activate maximal TNF- $\alpha$ secretion was $10 \mathrm{ng} / \mathrm{ml}$ (data not shown). The viability of PBMC in the presence of bacteria CM was tested by propidium iodide incorporation using flow cytometry (BDLSR and CELLquest software; Becton Dickinson, Le Pont de Claix, France). In some cases, PBMC were stimulated with lipoteichoic acid (LTA $100 \mathrm{ng} / \mathrm{ml}$; Sigma) for six hours in the presence or absence of bacteria CM.

TNF- $\alpha$ or IL-10 released by PBMC or THP-1 cells was assayed using commercial enzyme linked immunosorbent assays (ELISA kits; Duoset R\&D Systems, Lille, France).

\section{Analysis of LPS binding to THP-1 pro-monocytes in the presence of bacteria conditioned media by flow cytometry}

LPS has to bind to LPS binding protein (LBP) before LPS-LBP complexes can recognise the CD14 receptor. ${ }^{14}$ It can also bind to the toll-like receptor 4 (TLR4). In order to test whether lactic acid bacteria CM may interact with the binding of LPS to monocytes, we measured binding of LPS-FITC (Escherichia coli 055:B5; Sigma), used as a fluorescent marker, by flow cytometry. THP-1 cells were incubated for 48 hours at $2 \times 10^{6}$ cell $/ \mathrm{ml}$ in the presence of vitamin D3 $(12 \mathrm{ng} / \mathrm{ml})$ in order to upregulate CD14 receptor expression. ${ }^{15}$ Cells were preincubated for 30 minutes at $4^{\circ} \mathrm{C}$ with the optimal amount of bacteria $\mathrm{CM}$ and further incubated at $4^{\circ} \mathrm{C}$ for one hour in RPMI containing $10 \% \mathrm{SAB}$ as a source of LBP, and $2 \mu \mathrm{g} / \mathrm{ml}$ LPS-FITC. In some cases, bovine serum albumin $0.2 \%$ was used instead of SAB as a negative control to assess CDI4 independent LPS binding.

\section{Nuclear translocation of NF $\mathrm{NB}^{\mathrm{B}}$}

Nuclear factor $\kappa \mathrm{B}(\mathrm{NF \kappa B})$ activation is characterised by its nuclear translocation. This translocation was demonstrated on nuclear extracts by an electrophoretic migration shift assay.

THP- 1 cells $\left(10 \times 10^{6}\right.$ cells/ml in RPMI/FCS $\left.1 \%\right)$ were stimulated with $10 \mathrm{ng} / \mathrm{ml}$ LPS for 30 minutes in the presence or absence of half diluted CM filtrated fractions $<3 \mathrm{kDa}$, and nuclear and cytoplasmic extracts were prepared as previously described. ${ }^{16}$

Nuclear extracts $(5 \mu \mathrm{g})$ were placed in binding buffer (10 mM HEPES, pH 7.8, $100 \mathrm{mM} \mathrm{NaCl}, 1 \mathrm{mM}$ EDTA, and $10 \%$ glycerol) containing $1 \mu \mathrm{g}$ poly $(\mathrm{dI}-\mathrm{dC})$ and $0.5 \mathrm{ng}$ of ${ }^{32} \mathrm{P}-$ labelled DNA probe corresponding to the $\mathrm{\kappa B}$ site $\left(5^{\prime}\right.$ AGTTGAGGGGACTTTCCCAGG-3'; Promega, Charbonnières, France). Following incubation at room temperature for 30 minutes, samples were run on a $5 \%$ polyacrylamide gel in Tris-borate-EDTA buffer. The gel was dried, exposed to a PhosphorImager screen (Molecular Dynamics, Sunnyvale, California, USA), and the ImageQuant software (Molecular Dynamics) was used to perform densitometric analysis.

\section{Intestinal transport of active bacterial metabolites across the filter grown epithelial cell line HT29-19A under control and inflammatory conditions}

To analyse whether active bacterial metabolites can cross the intestinal barrier, we used filter grown intestinal cell monolayers. HT29-19A cells were seeded on microporous filters (Falcon) at a concentration of $0.8 \times 10^{6} \mathrm{cells} / \mathrm{cm}^{2}$ in Dulbecco's modified Eagle's medium supplemented with $10 \%$ FCS and $1 \%$ gentamicin. Three weeks later, this resulted in a tight polarised monolayer displaying a transepithelial

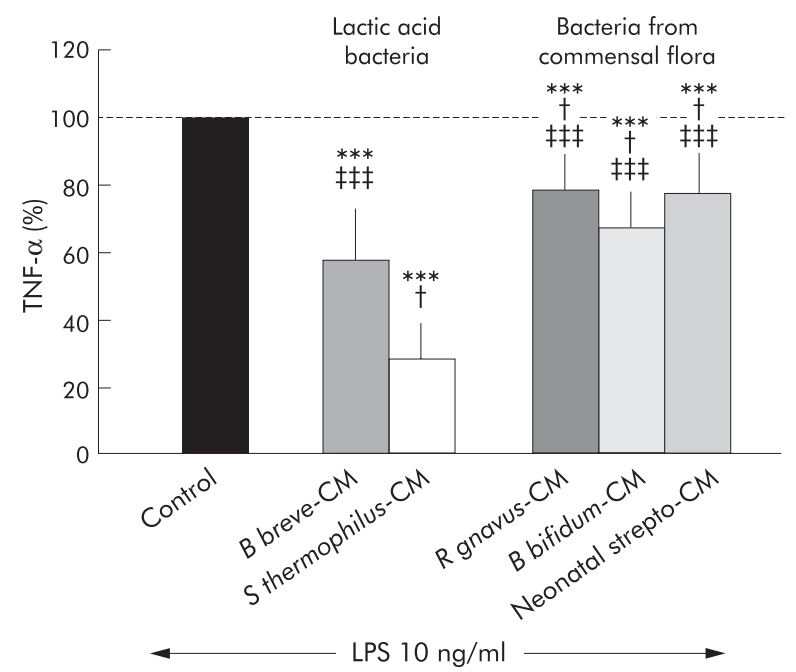

Figure 1 Comparison of the inhibitory effect of conditioned media (CM) from lactic acid bacteria (Bifidobacterium breve, Streptococcus thermophilus) and Gram positive bacteria from the dominant human microflora (Ruminococcus gnavus, Bifidobacterium bifidum, and neonatal streptococcus). Control bar (100\%) represents tumour necrosis factor $\alpha$ (TNF- $\alpha$ ) released by peripheral blood mononuclear cells (PBMC) stimulated with lipopolysaccharide (LPS) $10 \mathrm{ng} / \mathrm{ml}$. Addition of bacteria CM (at identical concentration of $2.5 \times 10^{5} \mathrm{CFU} / \mathrm{ml}$ ) to LPS stimulated PBMC induced a significant decrease in TNF- $\alpha$ secretion. Lactic acid bacteria were more inhibitory than bacteria from the human microflora. $\mathrm{n}=8$ experiments. ${ }^{* * *}$ Significantly different from control $(\mathrm{p}<0.0001)$; tsignificantly different from $B$ breve $(p<0.04)$; $\ddagger \ddagger \ddagger$ significantly different from $S$ thermophilus $(p<0.0001)$. 

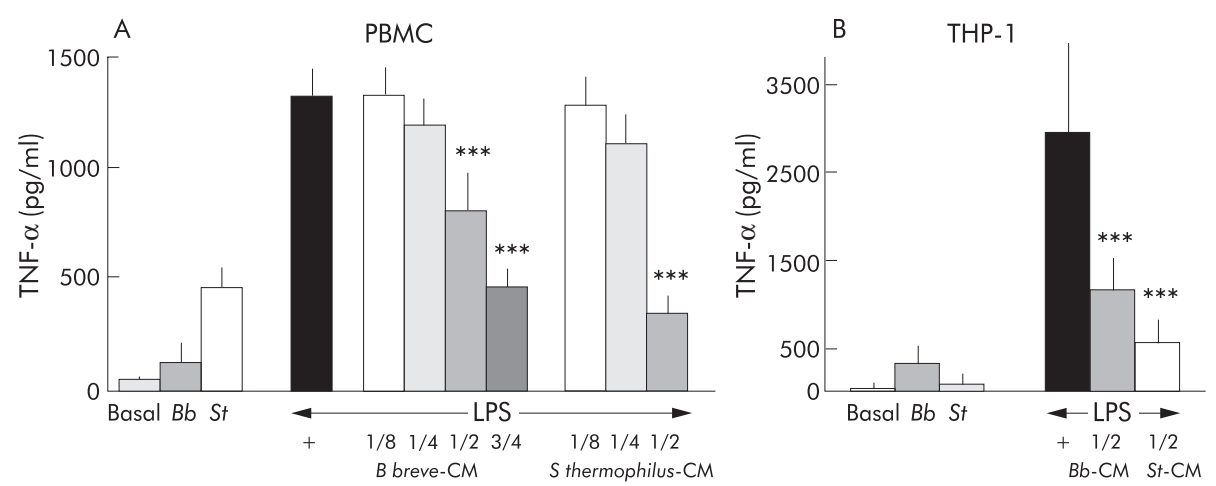

Figure 2 Effect of Streptococcus thermophilus (St) and Bifidobacterium breve (Bb) conditioned media (CM) on basal and lipopolysaccharide (LPS) induced tumour necrosis factor $\alpha$ (TNF- $\alpha$ ) secretion by peripheral blood mononuclear cells (PBMC) (A) and the pro-monocytic cell line THP-1 (B). Dose dependent inhibition of TNF- $\alpha$ secretion was observed in the presence of the conditioned media obtained from both bacterial strains. ${ }^{* *}$ Significantly different from LPS induced TNF- $\alpha$ secretion $(p<0.0001)$. $n=8$ (THP-1 experiments); $n=9-18$ (PBMC experiments).

electrical resistance of $\sim 150 \Omega \times \mathrm{cm}^{2}$. Cells were treated (inflammatory conditions) or not (controls) with $100 \mathrm{U} / \mathrm{ml}$ interferon (IFN) $-\gamma$ and $10 \mathrm{ng} / \mathrm{ml}$ TNF- $\alpha$ placed in basolateral compartments, and incubated for 48 hours. After two extensive washes with RPMI, bacteria CM (or RPMI as control) were added to the apical compartments. After 24 hours, media in the basolateral compartments were collected and tested for their capacity to inhibit LPS induced TNF- $\alpha$ secretion by PBMC, as described above. Electrical resistances of the intestinal cell monolayers were measured at the end of the experiment (that is, after basolateral treatment with IFN- $\gamma$ and TNF- $\alpha$ ) followed by 24 hour apical incubation with bacteria CM or RPMI. Epithelial cells secrete transforming growth factor $\beta$ (TGF- $\beta$ ), an anti-inflammatory cytokine known to inhibit TNF- $\alpha$ secretion. ${ }^{17}$ As this would mask the anti-inflammatory capacity of bacteria CM, the basolateral compartments were coated overnight with an anti-TGF- $\beta$ antibody (MAB240; R\&D) at a concentration of $2 \mu \mathrm{g} / \mathrm{ml}$ before adding bacteria CM to the apical compartment.

\section{Statistical analysis}

Statistical analysis was performed using the SAS package. Results are expressed as mean (SD) and comparisons of different parameters among the groups were performed using analysis of variance and non-parametric tests (Wilcoxon). Differences were considered significant for values of $\mathrm{p}<0.05$.

\section{RESULTS}

Effect of lactic acid bacteria and commensal bacteria CM on TNF- $\alpha$ secretion by LPS stimulated PBMC

Figure 1 indicates that both lactic acid bacteria and commensal bacteria $\mathrm{CM}$ used at a final concentration corresponding to $2.5 \times 10^{5} \mathrm{CFU} / \mathrm{ml}$ exerted an inhibitory effect on LPS induced TNF- $\alpha$ secretion. This inhibitory effect was significantly higher with lactic acid bacteria CM (43\% and $71 \%$ inhibition for $B$ breve and $S$ thermophilus CM, respectively) than with commensal bacteria CM $(21 \%, 32 \%$, and $22 \%$ for $R$ gnavus, $B$ bifidum, and neonatal streptococcus, respectively; $\mathrm{p}<0.04)$.

We also tested the inhibitory effect of commensal bacteria $\mathrm{CM}$ at their highest concentrations (that is, $0.65 \times 10^{6}$ to $1.65 \times 10^{8} \mathrm{CFU} / \mathrm{ml}$ ) and found an even more pronounced inhibition, reaching $36 \%, 77 \%$, and $96 \%$ for $R$ gnavus, $B$ bifidum, and neonatal streptococcus CM, respectively. Such high concentrations could not be explored with lactic acid bacteria $\mathrm{CM}$ as under identical culture conditions their growth was limited to 5 and $8 \times 10^{5} \mathrm{CFU} / \mathrm{ml}$, respectively.



Figure 3 Effect of Streptococcus thermophilus (St) and Bifidobacterium breve $(B b)$ conditioned media (CM) on lipoteichoic acid (LTA) induced tumour necrosis factor $\alpha$ (TNF- $\alpha$ ) secretion by peripheral blood mononuclear cells. Inhibition of TNF- $\alpha$ secretion was observed in the presence of $B b-C M$ ( $3 / 4$ dilution) and St-CM ( $1 / 2$ dilution).

***Significantly different from LTA induced TNF- $\alpha$ secretion $(p<0.0001)$ †††significantly different from LTA+Bb-CM ( $p<0.0001) ; \mathrm{n}=4-7$ separate experiments.

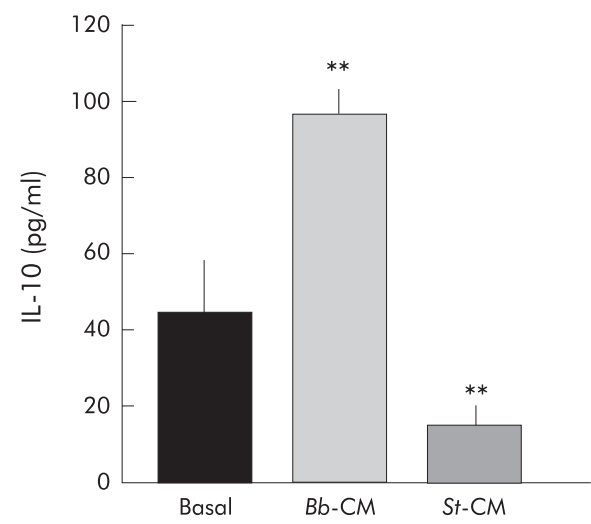

Figure 4 Effect of Bifidobacterium breve $(B b)$ and Streptococcus thermophilus (St) conditioned media (CM) on interleukin 10 (IL-10) secretion by peripheral blood mononuclear cells. $C M$ were used at their maximal concentration $(1 / 2$ and $3 / 4$ for $S$ thermophilus and $B$ breve, respectively). ${ }^{*}$ Significantly different from lipopolysaccharide $(p<0.0005) ; n=4$ 
Dose dependent effect of lactic acid bacteria CM on TNF- $\alpha$ secretion

Figure 2A shows that in the absence of any other stimulation, $S$ thermophilus CM stimulates TNF- $\alpha$ secretion (487 (192) $\mathrm{pg} / \mathrm{ml} ; \mathrm{p}<0.0003)$ and $B$ breve $\mathrm{CM}$ demonstrates a nonsignificant increase (150 (96) pg/ml) compared with basal secretion (49 (44) $\mathrm{pg} / \mathrm{ml}$ ). This basal stimulation could be due to the presence in the CM of residual Gram positive membrane components, such as peptigloglycan or LTA, known to stimulate TNF- $\alpha$ secretion. ${ }^{18} 19$ Both bacteria CM exerted a dose dependent inhibitory effect on LPS induced TNF- $\alpha$ secretion. Compared with LPS induced TNF- $\alpha$ secretion (1315 (413) $\mathrm{pg} / \mathrm{ml})$, significant inhibition of TNF- $\alpha$ secretion by PBMC was observed in the presence of $B$ breve $\mathrm{CM}$ at $\mathrm{l} / 2$ dilution (804 (400) $\mathrm{pg} / \mathrm{ml}, 39 \%$ inhibition; $\mathrm{p}<0.001$ ) and $3 / 4$ dilution (468 (172) pg/ml, 64\% inhibition; $\mathrm{p}<0.001)$. S thermophilus CM also inhibited LPS induced TNF- $\alpha$ secretion with a maximal effect at $1 / 2$ dilution $(71 \%$ inhibition; $\mathrm{p}<0.001), 3 / 4$ dilution being toxic to immune cells. The culture media used to produce bacteria CM, by themselves, did not inhibit TNF- $\alpha$ secretion (not shown). In THP-l cells (fig 2B) under basal conditions, $B$ breve CM displayed a non-significant increase (323 (101) pg/ml) in TNF- $\alpha$ secretion compared with basal secretion (46 (34) pg/ $\mathrm{ml}$ ) whereas $S$ thermophilus CM did not stimulate TNF- $\alpha$ secretion $(81(52) \mathrm{pg} / \mathrm{ml})$ in contrast with what was observed with PBMC. Again, in the presence of LPS, TNF- $\alpha$ secretion (2938 (501) ng/ml) was increased, and B breve or $S$ thermophilus CM highly inhibited (1160 (184) and 560 (124) ng/ml, respectively; $\mathrm{p}<0.001$ ) such secretion.

Viability studies using flow cytometry showed that $B$ breve CM did not induce cell death even at a high dose $(3 / 4$ dilution) as PBMC apoptosis was approximately $11 \%$ under control conditions and $13 \%$ in the presence of $B$ breve CM. However, incubation of $S$ thermophilus CM with PBMC led to a death rate of $20 \%$ at $1 / 2$ dilution but of $90 \%$ at the highest concentration ( $3 / 4$ dilution).

\section{Effect of bacteria CM on TNF- $\alpha$ secretion by LTA induced PBMC}

Figure 3 shows that LTA, a major compound of the Gram positive bacterial cell wall, stimulates TNF- $\alpha$ secretion (880 (147) $\mathrm{pg} / \mathrm{ml}$ ) and that both lactic acid bacteria CM inhibit LTA stimulated TNF- $\alpha$ secretion (383 (50) and 642 (39); $\mathrm{p}<0.0001$ for $B b$ and $S t C M$, respectively).

\section{Effect of bacteria CM on IL-10 secretion by PBMC}

IL-10 secretion by PBMC was identical in the presence or absence of LPS (not shown). Figure 4 shows that basal

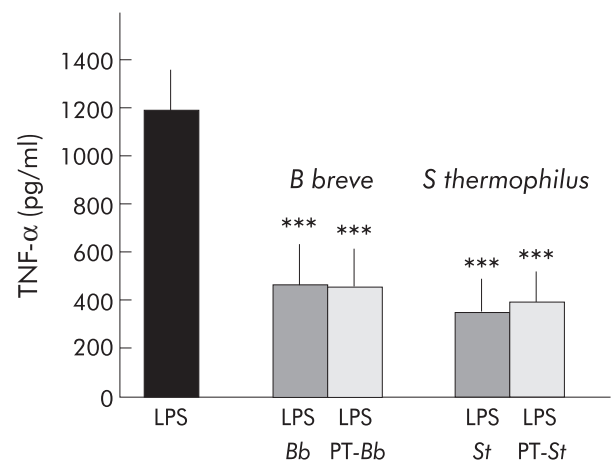

Figure 5 Effect of Bifidobacterium breve $(B b)$ and Streptococcus thermophilus $(S t)$ conditioned media (CM), after treatment with pepsin/ trypsin (PT), on lipopolysaccharide (LPS) induced tumour necrosis factor $\alpha$ (TNF- $\alpha$ ) secretion. Native and PT hydrolysed bacteria CM had the same inhibitory effect on LPS induced TNF- $\alpha$ secretion. ${ }^{* *}$ Significantly different from LPS $(p<0.0001) ; n=8-13$.
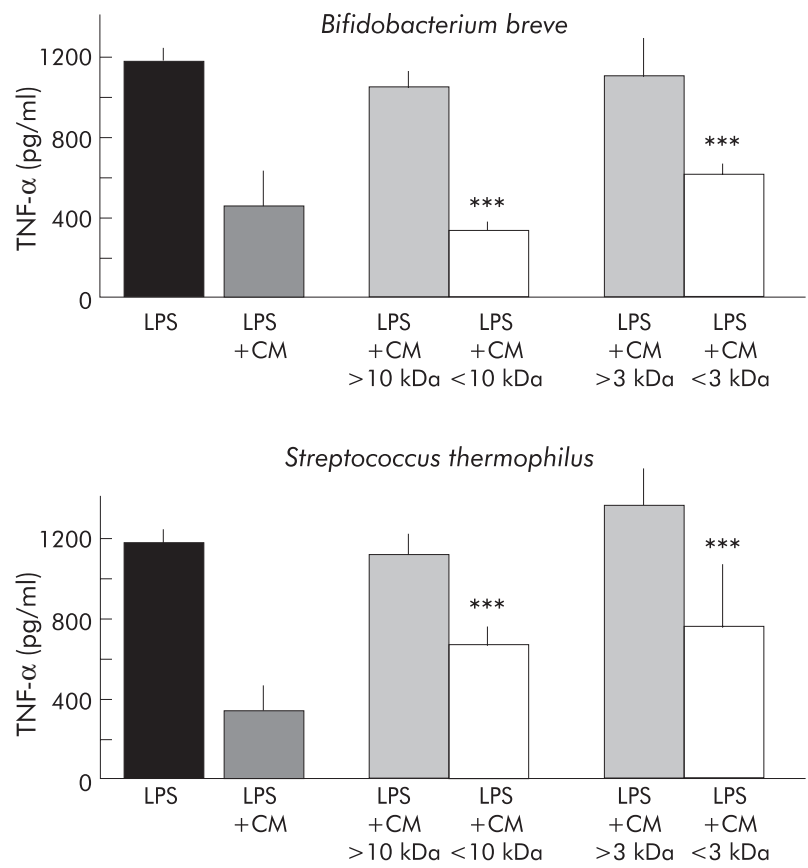

Figure 6 Assessment of the molecular weight of active bacterial metabolites. Ultrafiltration of bacteria conditioned media (CM) was performed on selective membranes (molecular weight cut off of 3 and $10 \mathrm{kDa}$ ). Retained and filtrated fractions were tested for their capacity to inhibit tumour necrosis factor $\alpha$ (TNF- $\alpha$ ) secretion. Ultrafiltrated CM were used at their maximal inhibitory concentration. Only filtrated but not retained fractions displayed inhibitory capacities, indicating the low molecular weight $(<3 \mathrm{kDa})$ of active bacterial metabolites.

${ }^{* * *}$ Significantly lower than lipopolysaccharide (LPS) and retained fraction $(\mathrm{p}<0.0001) ; \mathrm{n}=4-10$ separate experiments.

secretion of IL-10 (52 (27) pg/ml) was significantly increased in the presence of B breve CM (3/4 dilution) (98 (24) pg/ml; $\mathrm{p}<0.0005)$. In the presence of $S$ thermophilus CM $(1 / 2$ dilution), IL-10 secretion was significantly decreased (13 (5) $\mathrm{pg} / \mathrm{ml} ; \mathrm{p}<0.0006$ ) compared with basal secretion.

\section{Characterisation of active bacterial metabolites} Pepsin-trypsin hydrolysis

Pepsin/trypsin treated $B$ breve $(462$ (153) pg/ml) and $S$ thermophilus CM (394 (139) pg/ml) were found to have an inhibitory effect compared with control LPS stimulation ( 1185 (165) pg/ml; p<0.0001) (fig 5). Native and hydrolysed bacteria CM had the same inhibitory effect, indicating that digestive enzymes do not alter their inhibitory capacity and that active bacterial metabolites are probably not proteins.

\section{Selective ultrafiltration}

Figure 6 shows that filtrates containing metabolites $<10 \mathrm{kDa}$ still decreased TNF- $\alpha$ secretion $(330$ (46) pg/ml and 680 (96) $\mathrm{pg} / \mathrm{ml}$ for $B b$ and $S t$, respectively; $\mathrm{p}<0.0001$ ) compared with LPS induced secretion (1189 (66) pg/ml). Filtrates containing metabolites $<3 \mathrm{kDa}$ also significantly decreased TNF- $\alpha$ secretion (690 (74) pg/ml and 759 (325) $\mathrm{pg} / \mathrm{ml}$ for $B b$ and St, respectively; $\mathrm{p}<0.0001)$ whereas retained fractions did not, indicating that most of the active bacterial metabolites have a molecular mass lower than $3 \mathrm{kDa}$.

\section{Active bacterial metabolites inhibit LPS binding to THP- 1 cells}

As shown in fig 7, in the presence of LBP (contained in serum $\mathrm{AB})$, LPS-FITC binding to $\mathrm{CD} 14$ receptors expressed on mature THP-1 cells was small but significant (mean fluorescence intensity $7.0(0.4))$. There was also a small 


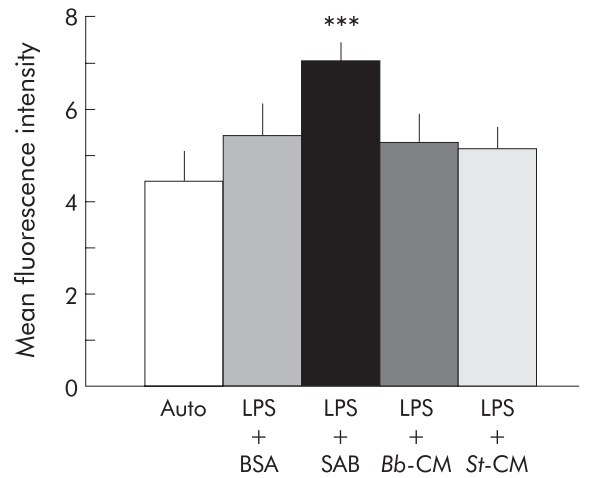

Figure 7 Effect of Streptococcus thermophilus (St) and Bifidobacterium breve (Bb) conditioned media (CM) on lipopolysaccharide (LPS)-FITC binding to differentiated THP-1 cells. Mean fluorescence intensity was determined by flow cytometry. Compared with autofluorescence, there was a small amount of binding of LPS to THP-1 cells in the presence of bovine serum albumin (BSA) (CD14 independent binding). This binding was significantly increased in the presence of LPS binding protein (contained in human serum $A B(S A B)$ ) (CD1 4 dependent binding). After pretreatment at $4^{\circ} \mathrm{C}$ with $S t-C M$ or $B b-C M$ in the presence of $S A B, C D 14$ dependent LPS-FITC binding to THP-1 cells was significantly inhibited. ***Significantly different from the other conditions $(p<0.0001) ; n=6$ separate experiments.

amount (non-significant) of binding of LPS-FITC in the absence of LBP (LPS+BSA). However, $B$ breve and $S$ thermophilus CM completely inhibited LBP dependent LPS binding to THP-1 cells (mean fluorescence $5.2(0.6)$ and 5.1 $(0.5) ; \mathrm{p}<0.0001)$. The culture media used to grow both lactic acid bacteria did not, by themselves, inhibit this binding.

Active metabolites from $B$ breve and $S$ thermophilus decrease NFKB nuclear translocation in THP- 1 cells In this study, active metabolites of molecular mass $<3 \mathrm{kDa}$ were used. As shown in fig 8, LPS stimulated nuclear translocation of $\mathrm{NF \kappa B}$ and the density of this band was arbitrarily taken as $100 \%$ activation. In the presence of LPS, $B$ breve and $S$ thermophilus $\mathrm{CM}$ (filtrated fraction $<3 \mathrm{kDa}$ ) inhibited LPS induced NFkB nuclear translocation by $34 \%$ and $35 \%$, respectively.

\section{Active bacterial products retain their anti-TNF- $\alpha$ properties after intestinal transport}

We tested the capacity of bacterial metabolites to cross the epithelial barrier as their anti-inflammatory effect should normally take place in the lamina propria where immune cells are located rather than in the intestinal lumen. As presented in fig 9A, basolateral compartments, potentially containing inhibitory factors after transepithelial transport of bacterial CM, were tested for their capacity to inhibit LPS induced TNF- $\alpha$ secretion by PBMC, under basal and inflammatory conditions. As shown in fig 9B, basolateral compartments obtained under basal conditions (epithelial control) had an inhibitory effect on TNF- $\alpha$ secretion (44\% and $45 \%$ inhibition under basal and inflammatory conditions, respectively; $\mathrm{p}<0.0001$ ). This suggests that epithelial cells by themselves release anti-TNF- $\alpha$ factors that may be distinct from TGF- $\beta$ as the culture plates are coated with antiTGF- $\beta$. Under basal conditions, $B$ breve CM were still able to inhibit TNF- $\alpha$ secretion $(\mathrm{p}<0.0012)$ following intestinal transport ( $S$ thermophilus $\mathrm{CM}$ also inhibited secretion although this was not significant $(\mathrm{p}=0.07))$ compared with epithelial controls. After treatment of intestinal monolayers with the inflammatory cytokines TNF- $\alpha$ and IFN $-\gamma, B$ breve and $S$ thermophilus CM further decreased TNF- $\alpha$ secretion to



Figure 8 Effect of Streptococcus thermophilus (St) and Bifidobacterium breve $(B b)$ conditioned media $(C M)$ on nuclear translocation of nuclear factor $K B(N F K B)$ in THP-1 cells. Electrophoretic migration shift assays were performed following extraction of nuclear proteins, and the presence of $N F \kappa B$ assessed using hybridisation with a ${ }^{32}$ P labelled DNA probe. Results are representative of two separate experiments. LPS, lipopolysaccharide.

$23(7) \%$, and $37(8) \%$ of LPS activated secretion, respectively $(\mathrm{p}<0.0001)$. Under inflammatory conditions, the inhibitory capacity of bacteria CM was higher than that observed under basal conditions $(p<0.02)$. As a control of the integrity of the epithelial barrier, the electrical resistance, R, of HT29-19A monolayers was measured in Ussing chambers following treatment with TNF- $\alpha$ and IFN- $\gamma$ for 48 hours and then incubation with bacteria CM for 24 hours in the apical compartments (fig 9C). Under basal conditions, HT29-19A monolayers had an electrical resistance R of 122 (59) $\Omega \times \mathrm{cm}^{2}$. $B$ breve CM did not significantly modify R ( 153 (44) $\Omega \times \mathrm{cm}^{2}$ ) compared with control monolayers whereas $S$ thermophilus CM decreased $R$ to $67 \quad(7) \Omega \times \mathrm{cm}^{2} \quad(\mathrm{p}<0.002)$. Under inflammatory conditions (IFN- $\gamma$ and TNF- $\alpha$ ), in epithelial controls, R significantly decreased (78 (19) $\Omega \times \mathrm{cm}^{2}$; $\mathrm{p}<0.0001) \quad$ compared with basal conditions (122 (59) $\Omega \times \mathrm{cm}^{2}$ ). This decrease was even more pronounced in the presence of bacteria CM ( $\mathrm{R}=29$ (14) and 24 (16) $\Omega \times \mathrm{cm}^{2}$, respectively, for $B$ breve and $S$ thermophilus $\mathrm{CM}$; $\mathrm{p}<0.0001$ ) indicating that bacterial metabolites do not display a curative effect on the inflamed epithelial barrier.

\section{DISCUSSION}

Beneficial effects have been observed with probiotic bacteria used as adjuvants in the treatment of various digestive diseases. The most convincing effect in humans has been observed in the treatment of pouchitis. ${ }^{6}$ However, the mechanisms operating in the improvement in inflammatory conditions associated with digestive diseases are not completely understood and are probably complex. The beneficial activity of probiotics may be exerted through the immunomodulation of gut associated lymphoid tissue. The suggestion that commensal bacteria may have a role in induction of antiinflammatory signals, as tested in intestinal epithelial cell lines, was reported in a study showing that non-pathogenic


pathway by preventing ubiquitination of I $\mathrm{K} B$ and therefore the release of proinflammatory cytokines. ${ }^{20}$ These results suggested that commensal bacteria, and perhaps probiotic bacteria, might induce downregulation of proinflammatory 

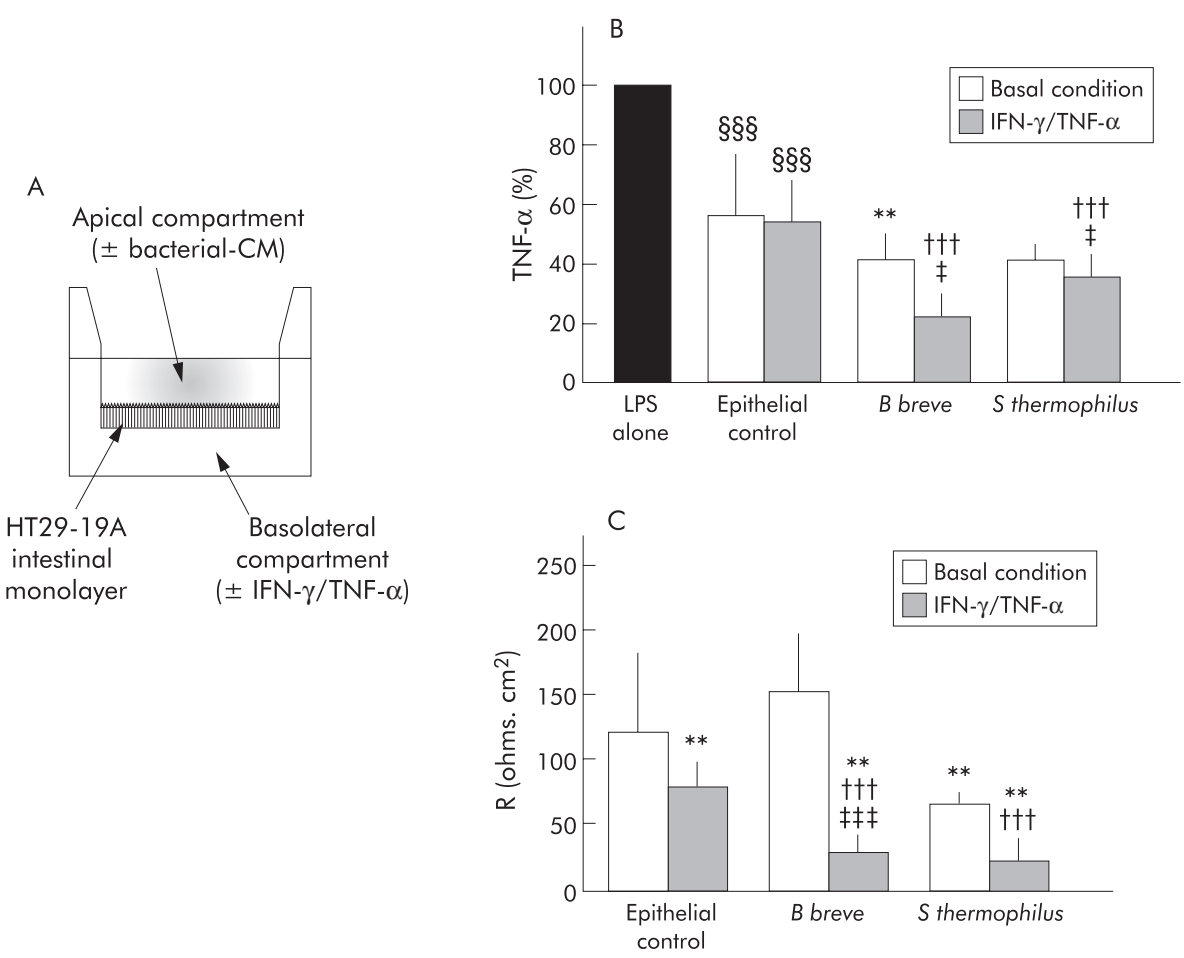

Figure 9 Inhibitory capacity of bacteria conditioned media (CM) after crossing the intestinal epithelial monolayer. (A) HT29-19A intestinal cells were grown as tight monolayers on microporous filters separating apical and basolateral compartments. After 48 hours of treatment with (or without) tumour necrosis factor $\alpha$ (TNF- $\alpha)$ /interferon $\gamma$ (IFN- $\gamma$ ), cells were washed and bacteria CM were added to the apical compartment for 24 hours. Basolateral compartments were then tested for their inhibitory capacity on TNF- $\alpha$ secretion. (B) Basolateral epithelial cell CM, by themselves (epithelial control), already inhibited lipopolysaccharide (LPS) induced TNF- $\alpha$ secretion. The inhibitory capacities of bacteria CM were retained after crossing the intestinal epithelial layer of HT29-19A cells, especially under inflammatory conditions. The inhibitory capacity of Bifidobacterium breve CM was retained after transepithelial transport, under basal and more extensively under inflammatory conditions. The inhibitory capacity of Streptococcus thermophilus CM was statistically significant under inflammatory conditions. **Significantly different from epithelial control under basal conditions $(p<0.0012)$; $+† \dagger$ significantly different from epithelial control under inflammatory condition $(p<0.0001)$; $\ddagger$ significantly different from bacteria CM under basal conditions $(p<0.02) ; \S \S \S$ significantly different from LPS alone $(p<0.0001) ; n=4-15$ separate experiments. (C) Electrical resistance of epithelial layers 48 hours after treatment with inflammatory cytokines, followed by incubation for 24 hours with S thermophilus and B breve CM or RPMl in the apical compartment. **Significantly different from epithelial control under basal conditions ( $p<0.002)$; ††tsignificantly different from epithelial control under inflammatory conditions $(p<0.0001)$; $\neq \ddagger \ddagger$ significantly different from $B$ breve $C M$ under basal conditions $(p<0.0001) ; n=10$ monolayers per condition.

signals mediated through $\mathrm{NF \kappa B}$, a transcription factor involved in the production of many proinflammatory cytokines or chemokines.

In the present study, secretion metabolites of two lactic acid bacteria ( $B$ breve and $S$ thermophilus) and to a lesser extent three commensal Gram positive bacteria ( $R$ gnavus, $B$ bifidum, and neonatal streptococcus) were shown to be capable, in vitro, of inhibiting LPS induced TNF- $\alpha$ secretion by immune cells.

The present results suggest the possibility of self-limiting properties of commensal bacteria with respect to their own proinflammatory capacities as commensal bacteria, which are part of the dominant microflora, also displayed a dose dependent anti-inflammatory effect. Therefore, the question arises as to the benefit of using probiotic bacteria when the commensal microflora has the same beneficial effects on inflammation. One of the advantages of probiotic bacteria could reside in maintaining a higher (although transient) bacterial density in the upper gastrointestinal tract, a location normally hosting very few bacteria. This "transient colonisation" may favour downregulation of inflammatory processes developing in intestinal areas which are normally not in contact with commensal microflora or in areas where the composition of the resident microflora is altered. It is possible that probiotics represent an "exogenous" microflora exerting a local beneficial effect during intestinal transit, and that continuous intake is needed to exert such an effect. By contrast, the resident microflora would exert such an effect permanently, at least in the distal part of the small intestine and colon.

$B$ breve $\mathrm{CM}$ was more efficient than $S$ thermophilus $C M$ in exerting anti-inflammatory properties, especially following intestinal transport, with no side effects on epithelial or immune cell viability. The inhibitory capacity of $B$ breve and $S$ thermophilus CM may not involve the same active metabolites as some discordance has been observed in experiments designed to better understand the mechanisms of the inhibitory effect (lower IL-10 secretion by $S$ thermophilus CM and lower inhibition of LTA induced TNF- $\alpha$ secretion).

Active metabolites seem to be non-protein molecules $(<3000 \mathrm{Da})$ but their exact nature remains to be investigated. Some bacterial metabolites, particularly short chain fatty acids such as butyrate, produced by bacterial fermentation of dietary fibres, have been shown to exert inhibitory effects on NFKB activation, especially in the presence of TNF- $\alpha$ both, in an intestinal epithelial cell line ${ }^{21}$ and in macrophages. ${ }^{22}$ In the present study, this possibility was excluded as bacteria CM did not contain significant amounts of butyrate. Indeed, butyrate concentration was very low (15 and $20 \mu \mathrm{M}$ for $B$ breve and $S$ thermophilus CM, respectively) suggesting that butyrate was not involved as active concentrations have been reported in the micromolar range.22 Substantial amounts of lactic acid were found (4.5 and $9 \mathrm{mM}$ for $B$ breve and $S$ thermophilus $\mathrm{CM}$, respectively) but at 
these concentrations, lactic acid did not inhibit LPS induced TNF- $\alpha$ secretion (data not shown).

It is interesting to note that even though lactic acid bacteria $\mathrm{CM}$ are obtained from a relatively small bacterial density $\left(\sim 2.5 \times 10^{5} \mathrm{CFU} / \mathrm{ml}\right)$, the inhibitory effect is significant, underlining the efficiency of the active bacterial metabolites. Indeed, in vivo, the density of probiotic bacteria orally administered is generally high $\left(\sim 10^{10} \mathrm{CFU} /\right.$ day $)$ and our results suggest that despite large amounts of bacteria being lost due to the hostile intestinal environment (gastric acidity, digestive enzymes, defensins), surviving bacteria may play a role in downregulating inflammation. The mechanisms by which bacterial secretion products inhibit LPS activation of immune cells are probably multifactorial. In the present study, bacterial products seem to limit access of LPS to CDI4 receptors on monocytes/macrophages. This is associated with lowering of $\mathrm{NF \kappa B}$ signalling in immune cells and downregulation of TNF- $\alpha$ secretion. Although intestinal macrophages do not express CD14 under basal conditions, their expression is upregulated under inflammatory conditions, ${ }^{23}$ underlining the potential beneficial effect of probiotic bacteria under these conditions. However, the mechanism involved in inhibition of TNF- $\alpha$ secretion may not rely solely on inhibition of the LPS receptor as bacteria CM also inhibited LTA induced TNF- $\alpha$ secretion, a process dependent on TLR-2. Thus the possibility that bacteria CM also act by affecting the intracellular signalling cascade leading to $\mathrm{NF \kappa B}$ activation has not been excluded.

$B$ breve CM also stimulated IL-10 secretion, a cytokine with anti-inflammatory properties. ${ }^{24}$ Indeed, IL-10 downregulates TNF- $\alpha$ secretion by macrophages ${ }^{25}$ and decreases MHC class II expression on antigen presenting cells. ${ }^{26}$ In atopic children, administration of Lactobacillus rhamnosus $G G\left(2 \times 10^{10} \mathrm{CFU}\right.$ daily) for a period of four weeks leads to increased levels of serum IL-10 and to increased production of mitogen induced IL-10 secretion by PBMC. ${ }^{27}$ In the same way, intragastric administration of Lactococcus lactis engineered to secrete IL-10 leads to a $50 \%$ decrease in dextran sulphate induced colitis in mice. $^{28}$

It is interesting that after crossing the epithelial barrier, bacteria CM still exerted an inhibitory effect, especially under inflammatory conditions. It was difficult to dissociate the inhibitory capacity of bacteria CM from that of intestinal epithelial cells (IEC) themselves as the latter are known to release suppressive factors, including prostaglandins and TGF- $\beta .^{29}{ }^{30}$ Although we tried to eliminate this problem by capturing TGF- $\beta$ in the basolateral compartment of filter grown epithelial cells using anti-TGF- $\beta$ antibodies, an inhibitory effect was still caused by epithelial cell CM, suggesting that either TGF- $\beta$ is not totally blocked by antiTGF- $\beta$ antibodies or that suppressive factors other than TGF- $\beta$ are released by IEC. However, addition of bacteria CM (especially from $B$ breve) significantly added to the epithelial inhibitory effect, suggesting that bacterial active metabolites by themselves help in downregulating inflammation. Two possibilities may explain such an inhibitory activity in the intestinal environment: (1) an indirect inhibitory effect linked to modulation of epithelial cell derived anti-inflammatory compounds by bacterial metabolites or (2) most likely, transepithelial passage of active bacterial metabolites across the epithelial barrier. The transepithelial pathway, along which bacterial metabolites may cross the epithelial barrier, could be paracellular as well as transcellular. Indeed, although it is well recognised that proinflammatory cytokines facilitate paracellular leakage to small molecules, increased transport of molecules along a transcellular pathway by transcytosis is also observed in the presence of IFN- $\gamma^{31}$ Alternatively, receptor mediated transport of active metabolites at the apical membrane of enterocytes could be involved.
Taken together, the present results indicate that both commensal Gram positive bacteria and the probiotic bacteria Bifidobacterium breve and Streptococcus thermophilus exert an anti-TNF- $\alpha$ effect, at least in vitro. In addition, the findings suggest that active metabolites released by probiotic bacteria during intestinal transit may cross the intestinal layer to exert anti-inflammatory effects. This would add to the suppressive tone of the intestinal microenvironment, under basal conditions, and help downregulation of inflammation under pathological conditions. Thus immunomodulation of the gut associated lymphoid tissue may explain, at least in part, the beneficial effects of probiotic bacteria as adjuvants in the treatment of digestive inflammation.

\section{ACKNOWLEDGEMENTS}

This work was partly supported by Blédina-SA and by financial assistance from the Princesse de Monaco foundation. We also acknowledge Dr Butel for her help in performing short chain fatty acids assays and Dr G Corthier for providing us with the commensal bacterial strains.

\section{Authors' affiliations}

S Ménard, C Candalh, J C Bambou, K Terpend, N Cerf-Bensussan, M Heyman, INSERM EMI-0212, Faculté Necker Enfants Malades, Paris, France

\section{REFERENCES}

1 Heyman M, Menard S. Probiotic microorganisms: how they affect intestinal pathophysiology. Cell Mol Life Sci 2002;59:1151-65.

2 Majamaa $H$, Isolauri E. Probiotics: a novel approach in the management of food allergy. J Allergy Clin Immunol 1997;99:179-85.

3 Canducci F, Armuzzi A, Cremonini F, et al. A lyophilized and inactivated culture of Lactobacillus acidophilus increases Helicobacter pylori eradication rates. Aliment Pharmacol Ther 2000;14:1625-9.

4 Madsen K, Cornish A, Soper P, et al. Probiotic bacteria enhance murine and human intestinal epithelial barrier function. Gastroenterology $2001 ; 121: 580-91$

5 Madsen KL, Doyle JS, Jewell LD, et al. Lactobacillus species prevents colitis in interleukin 10 gene-deficient mice. Gastroenterology 1999;116:1107-14.

6 Gionchetti P, Rizzello F, Venturi A, et al. Oral bacteriotherapy as maintenance treatment in patients with chronic pouchitis: a double-blind, placebocontrolled trial. Gastroenterology 2000;1 19:305-9.

7 Borruel N, Carol M, Casellas F, et al. Increased mucosal tumour necrosis factor alpha production in Crohn's disease can be downregulated ex vivo by probiotic bacteria. Gut 2002;51:659-4.

8 Gupta P, Andrew H, Kirschner BS, et al. Is lactobacillus GG helpful in children with Crohn's disease? Results of a preliminary, open-label study. J Pediatr Gastroenterol Nutr 2000;31:453-7.

9 Caplan MS, Miller-Catchpole R, Kaup S, et al. Bifidobacterial supplementation reduces the incidence of necrotizing enterocolitis in a neonatal rat model. Gastroenterology 1999;117:577-83.

10 Pena JA, Versalovic J. Lactobacillus rhamnosus GG decreases TNF-alpha production in lipopolysaccharide-activated murine macrophages by a contactindependent mechanism. Cell Microbiol 2003;5:277-85.

11 Prantera C, Scribano ML, Falasco G, et al. Ineffectiveness of probiotics in preventing recurrence after curative resection for Crohn's disease: a randomised controlled trial with Lactobacillus GG. Gut 2002;51:405-9.

12 Maassen CB, Holten-Neelen C, Balk F, et al. Strain-dependent induction of cytokine profiles in the gut by orally administered Lactobacillus strains. Vaccine 2000;18:2613-23.

13 Dabard J, Bridonneau C, Phillipe C, et al. Ruminococcin A, a new lantibiotic produced by a Ruminococcus gnavus strain isolated from human feces. Appl Environ Microbiol 2001;67:4111-18.

14 Lamping N, Dettmer R, Schroder NW, et al. LPS-binding protein protects mice from septic shock caused by LPS or gram-negative bacteria. J Clin Invest 1998; 101:2065-71.

15 Takahashi T, Nakamura K, lho S. Differentiation of myeloid cells and 1,25dihydroxyvitamin D3. Leuk Lymphoma 1997;27:25-33.

16 Courtois G, Whiteside ST, Sibley CH, et al. Characterization of a mutant cell line that does not activate NF-kappaB in response to multiple stimuli. Mol Cell Biol 1997:17:1441-9.

17 Imai K, Takeshita A, Hanazawa S. Transforming growth factor-beta inhibits lipopolysaccharide-stimulated expression of inflammatory cytokines in mouse macrophages through downregulation of activation protein 1 and CDI4 receptor expression. Infect Immun 2000:68:2418-23.

18 Bhakdi S, Klonisch T, Nuber P, et al. Stimulation of monokine production by lipoteichoic acids. Infect Immun 1991;59:4614-20.

19 Timmerman CP, Mattsson E, Martinez-Martinez L, et al. Induction of release of tumor necrosis factor from human monocytes by staphylococci and staphylococcal peptidoglycans. Infect Immun 1993;61:4167-72. 
20 Neish AS, Gewirtz AT, Zeng $\mathrm{H}$, et al. Prokaryotic regulation of epithelial responses by inhibition of IkappaB-alpha ubiquitination. Science 2000;289:1560-3.

21 Inan MS, Rasoulpour RJ, Yin L, et al. The luminal short-chain fatty acid butyrate modulates NF-kappaB activity in a human colonic epithelial cell line. Gastroenterology 2000;1 18:724-34.

22 Segain JP, Raingeard DLB, Bourreille A, et al. Butyrate inhibits inflammatory responses through NFkappaB inhibition: implications for Crohn's disease. Gut 2000:47:397-403

23 Grimm MC, Pavli P, Van de PE, et al. Evidence for a CD14+ population of monocytes in inflammatory bowel disease mucosa-implications for pathogenesis. Clin Exp Immunol 1995;100:291-7.

24 Asseman C, Mauze S, Leach MW, et al. An essential role for interleukin 10 in the function of regulatory $T$ cells that inhibit intestinal inflammation. J Exp Med 1999;190:995-1004.

25 Fiorentino DF, Zlotnik A, Mosmann TR, et al. IL-10 inhibits cytokine production by activated macrophages. J Immunol 1991;147:3815-22.
26 McBride JM Jung T de Vries JE, et al IL-10 alters DC function via modulation of cell surface molecules resulting in impaired T-cell responses. Cell Immunol 2002;215: 162-72

27 Pessi T, Sutas $Y$, Hurme $M$, et al. Interleukin-10 generation in atopic children following oral Lactobacillus rhamnosus GG. Clin Exp Allergy 2000;30:1804-8.

28 Steidler L, Hans W, Schotte L, et al. Treatment of murine colitis by Lactococcus lactis secreting interleukin-10. Science 2000;289:1352-5.

29 Koyama SY, Podolsky DK. Differential expression of transforming growth factors alpha and beta in rat intestinal epithelial cells. J Clin Invest 1989:83:1768-73.

30 Nathens AB, Rotstein OD, Dackiw AP, et al. Intestinal epithelial cells downregulate macrophage tumor necrosis factor-alpha secretion: a mechanism for immune homeostasis in the gut-associated lymphoid tissue. Surgery 1995; 1 18:343-50.

31 Terpend K, Blaton MA, Candalh C, et al. Intestinal barrier function and cow's milk sensitization in guinea-pigs fed milk or fermented milk. J Pediatr Gastroenterol Nutr 1998;28:191-8. 